\title{
The role of Human Resources in Strategy Formulation
}

\author{
Venet Shala
}

\begin{abstract}
Corporate strategy formulation is a very important process and requires serious and careful engagement. Any mistake in the first phase of strategic management (formulation) will result in problems in the next stages such as implementation and control.

Today, organizations of different sizes, small and medium, and large, in the process of strategy formulation need the involvement of qualified, competent and talented employees that would influence the creation of a successful strategy.

However, the main problem in designing an unsuccessful strategy lies in the fact that most companies in the process of strategy development involve high level hierarchical levels and consultants inside or outside the company, leaving aside most of the human resources that contribute to the success of the company.

Various literature has emphasized that strategy formulation is an essential step in turning a company's vision and objectives into reality. Therefore, the visionary leadership of companies should be oriented towards giving more importance to human resources during the process of strategy formulation and involve any team member who can contribute to the realization of organizational goals and organizational vision.

Through this paper we will present human resources at a higher level in terms of importance and provide conclusions and recommendations on how organizations today should value these strategic resources and achieve competitive advantage in the market.

In this paper we will give an overview of Kosovar companies, the process of strategy formulation in these companies and analyze how human resources are involved in the process and what importance is given to them by the company.
\end{abstract}

Index Terms - Strategy Formulation, Human Resources, Vision and Objectives.

\section{INTRODUCTION}

Strategy formulation is basically the planning and strategy of the future [1]. Strategy implementation is a process through which planned strategies are converted into the real actions which focus on achieving the aims and objectives of the organization [2]. Formulation, the second phase in the strategic management process, produces a clear set of recommendations, with supporting justification, that revise as necessary the mission and objectives of the organization, and supply the strategies for accomplishing them. In formulation, we are trying to modify the current objectives and strategies in ways to make the organization more successful. This includes trying to create "sustainable" competitive advantages - although most competitive advantages are eroded steadily by the efforts of competitors [3].

Published on July 31, 2020

Venet Shala, AAB College, Pristina, Kosovo.

(corresponding e-mail: venet.shala@ universitetiaab.com)
There are three aspects or levels of strategy formulation each with a different focus, which need to be dealt with in the formulation phase of strategic management. The three sets of recommendations must be internally consistent and fit together in a mutually supportive manner that forms an integrated hierarchy of strategy, in the order given. These levels of strategy formulation according to Rex C. Mitchell, are as follow:

Corporate Level Strategy: In this aspect of strategy, we are concerned with broad decisions about the total organization's scope and direction. Basically, we consider what changes should be made in our growth objective and strategy for achieving it, the lines of business we are in, and how these lines of business fit together. It is useful to think of three components of corporate level strategy: (a) growth or directional strategy (what should be our growth objective, ranging from retrenchment through stability to varying degrees of growth - and how do we accomplish this), (b) portfolio strategy (what should be our portfolio of lines of business, which implicitly requires reconsidering how much concentration or diversification we should have), and (c) parenting strategy (how we allocate resources and manage capabilities and activities across the portfolio -- where do we put special emphasis, and how much do we integrate our various lines of business).

Competitive Strategy (often called Business Level Strategy): This involves deciding how the company will compete within each line of business (LOB) or strategic business unit (SBU).

Functional Strategy: These more localized and shorterhorizon strategies deal with how each functional area and unit will carry out

its functional activities to be effective and maximize resource productivity.

Strategic management is an important for each organization because of their importance in improving the organization's ability to solve problems and deal with it, to take collective decisions, to optimize the use of resources and possibilities, to achieve interaction with the external environment and achieve greater profits and financial returns that support the existence and continuation of the institution in the long run.

The purpose of this research is to make an additional contribution to how an organization can be developed by efficiently engaging human resources in the strategy formulation phase. Human resources strategic resources of a business or organization, especially when they are considered as an important asset. Therefore, increasing the importance of human resources as one factor for the success of the firm increases the importance of studying this specific area and its implications in the formulation phase, as the most important and difficult phase of Strategic Management. This article is primarily aimed at exploring the 
nature of key human resource management, strategic management process problems and how they can contribute to a successful strategy formulation.

\section{Significance Of The Study}

The importance of this article stems from the following:

1. The article will contribute to emphasizing the role of human resources in the strategy formulation phase

2. The findings of this paper will assist senior management and experts in strategic management to include all hierarchical levels in the organizational strategy formulation phase.

\section{LITERATURE REVIEW}

\section{A. Nature of Strategic Management}

Despite its importance, strategy formulation and strategy implementation do not consistently guarantee high organizational performance. Even well managed organization can sometimes hit capabilities for short periods due to adverse conditions beyond the ability of management to anticipate or respond to them. It is the responsibility of management to regulate adverse conditions by undertaking strategic safeguards and managerial approaches that can overcome this phenomenon. However, the essence of good strategy creation is to build a strong and flexible position to ensure successful performance, despite unpredictable and unexpected external factors [4]. Strategic management always focuses on the intended purpose. The future is always uncertain. Therefore, strategic decisions are always incomplete and sometimes these are based on false information. It may lead to further problems. The strategic manager should always aim to achieve the organization's predetermined goal. Further, organizations need to work with brevity and variety. Thoughts must become actions. Actions will lead to results. Outcome-driven action is a key need at all times [5].

\section{B. Human Resources Development}

According to Armstrong [6], Human Resource Management (HRM) is defined as a strategic and coherent approach to managing an organization's most valued assets the people who work there who individually and collectively contribute to achieving its objectives. From this definition, we can conclude that HRM or simply RH is a function in organizations created to maximize employee performance in service of their employer's strategic objectives [7]. RH is concerned primarily with how people are managed within organizations, focusing on policies and systems [8]. Human resource departments and units in organizations are typically responsible for a number of activities, including employee recruitment, training and development, performance appraisal and remuneration (e.g., payroll and benefits management) [9].

$\mathrm{RH}$ is also concerned with industrial relations, that is, balancing organizational practices with regulations deriving from collective agreements and government laws [10]. HRM is a product of the human relations movement of the early 20th century, when researchers began documenting ways of creating business value through strategic workforce management. The function was initially dominated by transactional work such as payroll and benefits management, but due to globalization, enterprise consolidation, technological advancement and further research, HRM now focuses on strategic initiatives such as mergers and acquisitions, talent management, planning success, industrial and employment relationships, ethical considerations, diversity and inclusion. These, among other initiatives, contribute to the understanding of Human Resource Management as a contemporary issue due to its sustainable evolutionary nature [12].

We see HRM as a competency-based approach to human capital management focused on developing sustainable, imperfect and imitative human resources. Developing resources with such characteristics is key to sustained competitive advantage, especially since, as Gardner [13] observes, "the primary source for firms competing in the new economy is no longer land, capital or strong assets, but human capital needed to adapt organizations to global competition and maximize the benefits associated with the current technological boom ". As an approach to the process of managing people in organizations, HRMS is not linked to human resources strategy. Indeed, formulating and adopting an $\mathrm{RH}$ strategy to "harmonize $\mathrm{RH}$ practices with strategic goals" [14].

\section{Role Of Human Resources In StRAtegy FORMULATION}

According to Bahtijarević-Šiber [15], the processes of strategic management and strategic management of human resources are highly interdependent and interactive processes that significantly affect one another. The main strategy shows how to achieve long-term goals. Accordingly, the core strategy can be defined as a master plan of activities through which a particular organization aims to achieve its long-term goals in a dynamic environment. It shows how the goals will be achieved or the business activities will be implemented. The types of strategies are useful for classifying the ways in which different organizations want to be competitive in some activities. However, it is also necessary to understand the implications of different strategies in human resources [16]. The core strategy allows for a significant volume of activities. In general, a particular business may try to reach a larger market share by increasing the current rate of use of their products by consumers, by attracting buyers to their competitors, or by raising the interest of non-users those who have not yet used / purchased their products) in their products or services. On the other hand, each of those activities suggests specific sets of alternatives (activities). This is why it is very important to distinguish between the specifics of certain strategies and their concentration, because the strategy actually represents a perception of the factors of existence and ways of achieving goals in given circumstances, and bears the stamp of the capabilities and aspirations of the final management of the given organization [17].

New human resource management for the 21 st century must play a strategic role by contributing to the process of 
strategy formulation and being a strategic partner in the implementation of these strategies. HR practices should be designed in accordance with the organization's strategies taking into account the essential human resource needs. In parallel, organizations may be able to be more flexible, flat, and agile in order to cope with changes in the competitive environment by gaining competitive advantage with their HR assets. HR professionals need to lead smarter organizations by encouraging individuals to exercise more initiative, autonomy, and responsibility by providing tools and techniques that improve their effectiveness and enable critical competencies through ongoing learning opportunities [11].

\section{RESEARCH RESULTS}

A sample of this paper are 40 small and medium-sized businesses in Kosovo, which have been the case study to produce relevant results on the importance of Human Resources in the strategy formulation phase. The method of interviewing through the questionnaire was used, the results were also extracted and are presented graphically as follows:

Question research 1: Human resources play a key role in successful company formulation

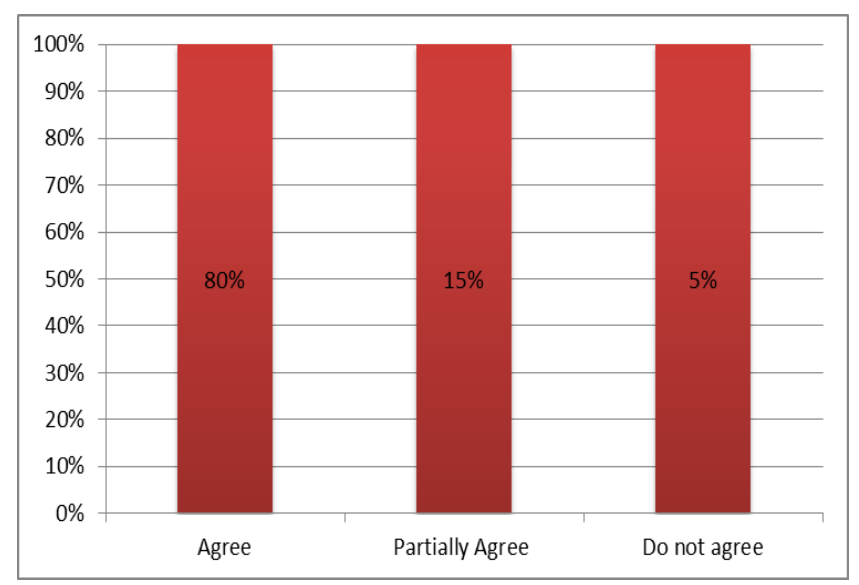

In the question whether human resources play a major role in the strategy formulation phase, out of 40 companies surveyed, 32 or $80 \%$ of them think that human resources are the main factor that results in successful formulation, 6 of them or $15 \%$ partially agree and only 2 of them or $5 \%$ disagree. Our hypothesis is supported by research and stands as true.

Question research 2: Human resources are well organized during the strategy formulation phase

21 or $53 \%$ of small and medium-sized enterprises in Kosovo agree that human resources are well organized when formulating a strategy, while a very large proportion 19 or $48 \%$ do not think that $\mathrm{RH}$ are well organized and the importance of these resources is overlooked. during this phase and are not given the space needed to contribute to the achievement of organizational goals. Our hypothesis is supported by research, but it is disturbing that the majority asserts the opposite.

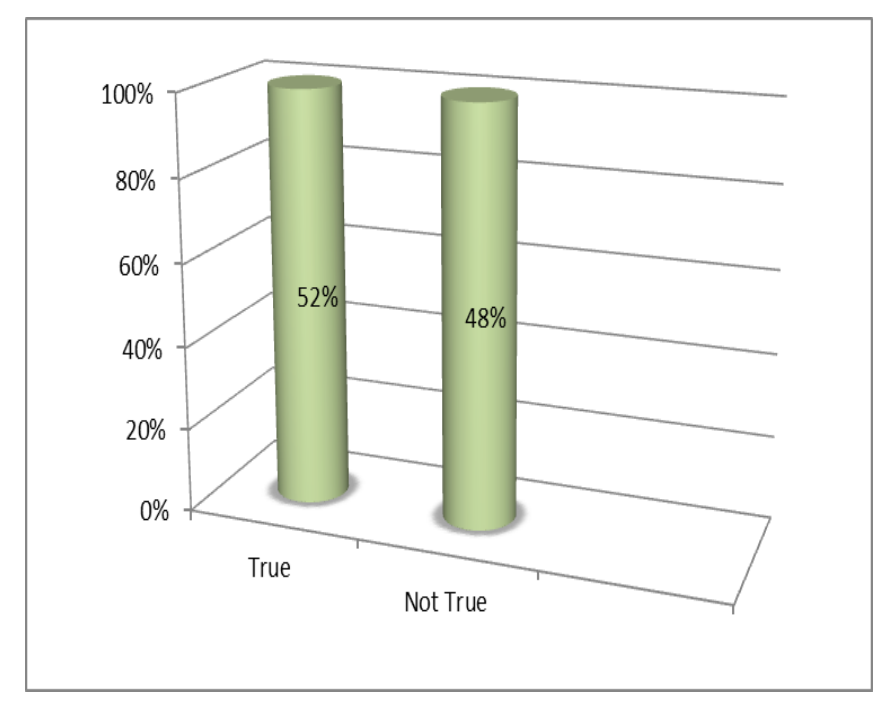

Question research 3: Firms that have qualified human resources result in successful strategy formulation in relation to firms that do not possess these resources

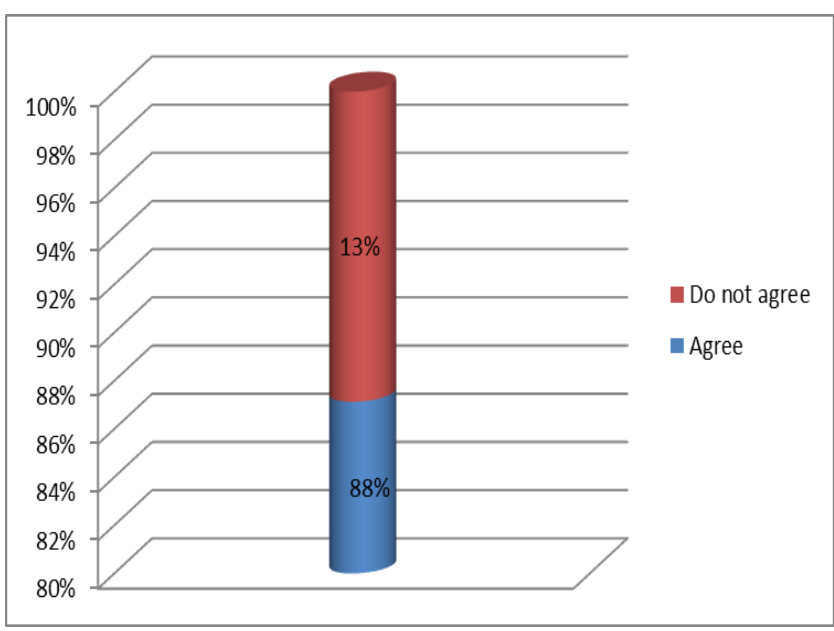

Asked if firms with qualified human resources result in successful strategy formulation in relation to firms that do not possess these resources 35 or $88 \%$ of the respondents agree unanimously and only 5 or $13 \%$ disagree. This hypothesis is proven to be correct and emphasizes once again that firms should invest in human resources and treat them as strategic factors during strategic processes.

\section{CONCLUSION AND RECOMMENDATION}

Organizations in order to have a greater reputation in the global marketplace than other companies need to have qualified HR managers who will be competent to train new employees and reward them on the basis of commitment and merit. Motivated employees will thus contribute to successful formulation and the next stages

Organizations should use advanced technology in day-today processes, especially in the process of recruiting, training employees, etc.

Human resources should be well organized during the strategy formulation phase, in order to have a successfully strategy formulation.

Research has confirmed that firms that have qualified human resources result in successful strategy formulation in 
relation to firms that do not possess these resources.

As a general recommendation, organization those days should place greater importance on qualified human resources, retain these resources and train them on all stages of strategic management, especially in the formulation phase to avoid errors in other follow-up stages.

\section{REFERENCES}

[1] Reilly, Caldwell \& Chat man 2010, how leadership matters: effects of leaders alignment on strategy implementation, journal of leadership quarterly21 104-113

[2] Fourier \& Jacob 2010, the role of strategic leadership in strategy implementation journal of university of Johannes berg/

[3] Strategy Formulation" Rex C. Mitchell, Ph.D. (June 2009)

[4] Journal of Comprehensive Research, Volume 5, Page 17 Strategic Management Process Strategic Management Process Dr I. Chaneta Department of Business Studies Faculty of Commerce University of Zimbabwe

[5] Business Policy and Strategic Management, G. V. Satya Sekhar, December 2009

[6] Armstrong, M. (2006) A Handbook of Human Resource Management Practice. 10th Edition, Kogan

[7] Johnason, P. (2009). HRM in changing organizational contexts. In D. G. Collings \& G. Wood (Eds.), Human resource management: A critical approach (pp. 19-37). London: Routledge.

[8] Collings, D. G., \& Wood, G. (2009). Human resource management: A critical approach. In D. G.

[9] Paauwe, J., \& Boon, C. (2009). Strategic HRM: A critical review. In D. G.

[10] Klerck, G. (2009). Industrial relations and human resource management. In D. G. Collings \& G. Wood (Eds.), Human resource management: A critical approach (pp. 238-259). London: Routledge.Page Publishing, London.

Schoonover, S.C. (2010) Human resource competencies for the new century,[Online],available: $\quad$ http://www.schoonover.com/pdf/HR competencies for the new centuryfinal.pdf[16 December 2010].

[11] Defining Human Resource Management (HRM) Dr. Ruth Tubey, Phd1; Kipkemboi Jacob Rotich (M.Phil) 2; Dr. Alice Kurgat, Phd, European Journal of Business and Management www.iiste.org ISSN 2222-1905 (Paper) ISSN 2222-2839 (Online) Vol.7, No.9, 2015

[12] Wright, P.M. and Gardner, T.M. (2002). 'Theoretical and empirical challenges in studying the HR practice \pm (Rm performance relationship' in The New Workplace: A Guide to the Human Impact of Modern Working Practices. D. Holman, T. Wall, C. Clegg, P. Sparrow and A. Howard (eds). Chichester: John Wiley and Sons.

[13] Lawler, E., Ulrich, D., Fitz-Enz, J., \& Madden, J. (2003). Human resources business process outsourcing:Transforming how HR gets its work done. SanFrancisco, CA: Jossey-Bass

[14] Bahtijarević-Šiber, F. (1999): Menadžment ljudskih potencijala, Golden marketing, Zagreb, 151

[15] Leopold, J., Harris, L. (2009): The Strategic Managing of Human Resources, 2nd edition., Prentice Hall, London, 313-315.

[16] Todorović, J. (2003): Strategijski i operativni menadžment, Conzit, Beograd, 174

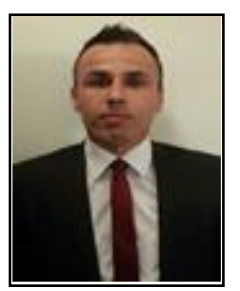

Venet Shala. PhD Venet Shala is a professor at the Faculty of Economics, AAB College, Kosovo. The narrow field of his study is the sciences of management, where he mainly teaches subjects in the field of management, leadership, entrepreneurship and business strategy. He earned a $\mathrm{PhD}$ from the Faculty of Economics, University of Pristina in 2012 with the title "The role of strategic management for SMEs growth in Kosovo". Professor Shala, has published dozens of scientific papers in international journals with impact factor and has participated in many local and international conferences and symposiums. He has more than 10 years of experience as a lecturer at several colleges and universities. For several years he has been engaged as a staff member of the European Union in Kosovo and has been directly involved in financial management, investments and capital projects. He also had been engaged in other Consulting Companies offering training and consultancy services and a lot of local and international projects. 